\title{
Microalgae isolation and selection for the treatment of landfill leachate
}

\author{
A. Paskuliakova, S. Tonry \& N. Touzet \\ School of Science, Centre for Environmental Research Innovation and \\ Sustainability (CERIS), Institute of Technology, Ireland
}

\begin{abstract}
The use of microalgae in remediation has been researched for a variety of waste effluents, yet algal remediation of landfill leachate is somewhat less explored. Very high levels of pollutants, such as ammonia nitrogen, salts and recalcitrant organic matter are present in landfill leachate and render it toxic to many organisms. Thus the selection of suitably tolerant microalgal strains is crucial for phycoremediation attempts. Other factors such as temperature and light requirements and the variable composition of landfill leachates also need to be incorporated into the remediation strategy.

This study focused on isolating microalgae strains from different environments in the North-West of Ireland, which might have the potential to use leachate pollutants as their source of nutrients. A screening process was applied to select the most promising strains which was followed by a preliminary assessment of nutrient depletion.

Altogether 34 strains were obtained from marine, freshwater and polluted environments. Further screening yielded 16 strains capable of growth in leachate samples to varying degrees. Generally, the strains isolated from landfill leachate itself appeared to perform better, while some freshwater and marine species could adapt if the leachate was appropriately diluted. A preliminary nutrient depletion experiment with the chlorophyte strain Chlamydomonas sp. SW13aLS grown on $10 \%$ permeate leachate indicated a substantial reduction in nutrients such as ammonia-nitrogen (93\%) and nitrate (54\%) when supplemented with phosphorus.

The results demonstrate the possible application of microalgae for the treatment of leachate when grown under limited light and relatively low temperature; however nutrient limitation could be a key inhibitory factor requiring optimisation. Keywords: phycoremediation, landfill leachate, microalgae, nutrient limitation.
\end{abstract}




\section{Introduction}

Phycoremediation is a process availing of the ability of microalgae to remove or biotransform inorganic and organic pollutants from wastewater [1]. Leachate, a wastewater originating from landfill sites and saturated with decomposition products from landfill waste, is a complex and challenging substrate to treat. Its composition varies and is generally dependent on a variety of factors [2].

Landfill leachate, in comparison with more researched phycoremediation applications such as municipal wastewater or fishpond discharges has higher concentrations of dissolved salts, especially chlorides and extremely high concentrations of ammonia-nitrogen, which can be toxic to many organisms. Thus far, most raw landfill leachate phycoremediation attempts have required it to be diluted to make any microalgal growth possible $[3,4]$. The selection of suitable species and strains is important. The most common in the literature in relation to remediation are freshwater chlorophytes, specifically Scenedesmus spp., Chlorella spp. and Chlamydomonas spp. [3-7]. A Scottish study that used marine species for the treatment of sewage wastewater was applied to a facility being situated near the shoreline so it could be diluted with sea water [8]. Similarly, in China, municipal wastewater diluted with seawater has been successfully used as growth medium for the marine microalgae Nannochloropsis sp. [9]. However, Aravantinou et al. [10] who evaluated the remediation ability of both marine and freshwater species noted that although the growth rates of marine microalgae were higher, nutrient removal was inferior for the marine species examined.

Throughout the literature the species often selected for phycoremediation studies are: (1) either isolated from the wastewater itself; (2) isolated from various environments and subjected to a screening procedure with criteria relevant to a particular application; or (3) based on prior knowledge of which species tend to be present in a wastewater type and thus can be purchased from culture collections.

In the present study, several different sampling sites were selected in northwest Ireland for species isolation with potential application to treatment of landfill leachate. These included various freshwater, marine and polluted environment (landfill leachate) microalgae. A screening procedure was applied to evaluate the tolerance of these strains to some pollutants expected to have an inhibitory effect on their growth (high salt content and ammonia-nitrogen). A selection of strains able to grow in landfill leachate was obtained for future studies. A preliminary nutrient depletion experiment was set up with one strain to estimate other possible factors that should be included in future studies (i.e. phosphorus limitation).

\section{Materials and methods}

\subsection{Strain isolation}

Microalgae were isolated from different environmental habitats in the North West of Ireland in 2012 and 2013 and from samples of landfill leachate collected in 2013 and 2014 at a municipal landfill site in Northern Ireland. Monocultures were obtained through single cell isolation into $\mathrm{f} / 2$ medium. In the case of non-marine species, the cultures were isolated into $\mathrm{f} / 2$ medium that was appropriately diluted 
with water of lower conductivity or autoclaved (wastewater) leachate. Cultures were brought up in an incubator at a temperature of $15^{\circ} \mathrm{C}$ and light cycle of 14:10 hours (light:dark) (Illuminance: 1667 lx, Photosynthesis photon flux density (PPFD): $\left.22 \mu \mathrm{mol} \cdot \mathrm{m}^{-2} \cdot \mathrm{s}^{-1}\right)$.

\subsection{Microscopy and counting techniques}

Species were characterised via light microscopy observations and with the aid of identification manuals $[11,12]$. Cell size was determined after fixing cells with formalin or Lugol's iodine and measuring their dimensions with the aid of a calibrated ocular micrometer scale at $\times 400$ magnification. Cell concentration was estimated either by counts with a Neubauer chamber or counts through focal view in 96-well plates using an inverted microscope.

\subsection{Molecular and phylogenetic analyses}

Partial PCR amplification of the large subunit (28S) ribosomal gene was conducted according to Touzet et al. [13]. Total genomic cellular DNA was extracted with the use of the VWR OMEGA BIO-TEK Plant DNA kit D348501 according to the manufacturer's instructions "Short protocol".

Partial large subunit ribosomal RNA gene sequences were compared to those present in Genbank's library by BLAST analysis (http://blast.ncbi.nlm.nih.gov //Blast.cgi) to indicate higher level taxonomic group allocation. A number of sequences of typical representatives of major taxonomic groups were also downloaded to visualise the genetic similarity of isolated species within these taxonomic groups. Initial alignments were made and edited with Genedoc and Clustal-X.

A non-rooted phylogenetic tree was generated with the use of "Phylogeny.fr" platform (http://www.phylogeny.fr/version2_cgi/index.cgi). Phylogeny.fr analysis involves alignment (MUSCLE v3.7), curation using Gblocks (v0.91b), reconstruction of phylogenetic tree using maximum likelihood method (PhyML v3.0) and graphical output and edition is provided by TreeDyn v198.3. Default settings were used [14-18].

\subsection{Landfill leachate collection}

Samples were collected at three points of the leachate treatment process: raw leachate, process leachate (or permeate) which is treated effluent after the anoxic tank in the MBR (Membrane Bioreactor) plant and treated leachate which is the final effluent from the MBR plant. Samples were stored at $<5^{\circ} \mathrm{C}$. Leachate samples were collected in March 2013 and April 2014.

\subsection{Landfill leachate physicochemical analyses}

Results for physico-chemical parameters of raw and treated leachate were obtained from certificates of analyses for environmental monitoring, which were carried out by the landfill operator.

Phosphate $\left(\mathrm{PO}_{4}^{3-}-\mathrm{P}\right)$, total oxidised nitrogen (TON) and total ammonia nitrogen (TAN) were determined spectrophotometrically based on APHA methods 
(Standard Methods for the Examination of Water and Wastewater) adapted to the Aquakem 250 autoanalyser. Samples were filtered through $0.45 \mu \mathrm{m}$ filter prior to the analyses.

\subsection{Physiological screening for strain selection}

Microalgae were subjected to a number of tolerance experiments whereby growth was monitored in media of different conductivity (to account for salt tolerance) and different dilutions of landfill leachate (ammonia and other toxicants tolerance). Light and temperature regimes were as per Section 2.1.

\subsubsection{Stress response to different conductivity levels}

The ability of strains to survive and grow in different salinities was observed in 24-well plates. The cell growth was monitored at intervals of several days by cell counts (focal view). Marine species were inoculated into $\mathrm{f} / 2$ medium of conductivity (2.0-2.4) and (16.0-17.5) $\mathrm{mS} / \mathrm{cm}$ while conductivity (49.0-53.0) $\mathrm{mS} / \mathrm{cm}$ was used as control. As most effluents are not expected to have conductivity above 16.0, all but the marine species were studied only at conductivity (2.0-2.4) and (16.0-17.5) $\mathrm{mS} / \mathrm{cm}$ with conductivity (2.0-2.4) being used as control. Experiments were conducted in duplicates due to logistical constraints and the relatively high numbers of strains to screen.

\subsubsection{Stress response to different leachate substrates}

Ammonia tolerance experiments were set up in 96-well plates in three different substrates: treated leachate, $25 \%$ dilution of permeate and $25 \%$ dilution of raw leachate (Feb 2013) that correspond to a concentration of $\sim 10 \mathrm{NH}_{4}^{+}-\mathrm{N} \mathrm{mg/l}$, $\sim 50 \mathrm{NH}_{4}^{+}-\mathrm{N} \mathrm{mg} / \mathrm{l}$ and $\sim 125 \mathrm{NH}_{4}^{+}-\mathrm{N} \mathrm{mg} / \mathrm{l}$, respectively. Growth was compared to a $\mathrm{f} / 2$ medium control. One single count was carried out on cultures that showed survival after a number of days based on previous growth experiments. Experiments were conducted in duplicates.

The strains that showed some growth were further evaluated on $25 \%, 35 \%$ and $50 \%$ permeate for growth as a compromise between treated and raw leachate.

\subsection{Selection process after screening}

\subsubsection{Stress response to different conductivity levels}

Growth of individual strains in media of different conductivities was expressed through relative increases. These are n-fold increases relative to day 0 count in media of each salinity.

$$
n \text {-fold increase }=\frac{\text { cell count on day } x\left[\frac{\text { cells }}{\mathrm{ml}}\right]}{\text { cell count on day } 0\left[\frac{\mathrm{cells}}{\mathrm{ml}}\right]}
$$

The maximum relative increases were compared to the maximum increase in the control to show the effect of media of different conductivities on the growth of each strain.

$$
\%=\frac{(\max (n-\text { fold cell no increase in media of studied conductivity })-1(\text { day } 0))}{(\max (\mathrm{n}-\mathrm{fold} \text { cell no increase in control })-1(\text { day } 0))} .100 \%
$$

The biovolume increases were also compared to take into account different cell sizes. 


\subsubsection{Stress response to different leachate substrates}

The potential to grow in different landfill leachates was evaluated and scores were allocated based on the ability of strains to grow and also on the biovolume increases in the substrate. Based on the results from the screening tests, all microalgae strains were divided into four groups of tolerance: high, medium, low and not suitable.

\subsection{Preliminary nutrient depletion experiment}

One strain from the group of highly tolerant strains was selected at random (SW13aLS) and used in a preliminary nutrient depletion experiment. Three sets of duplicates of $10 \%$ permeate leachate diluted with autoclaved deionised water with the same initial cell concentrations were prepared. Two flasks were supplemented with phosphorus ( 40 mg/l $\left.\mathrm{PO}_{4}^{3-}-\mathrm{P}\right)$ and two flasks were supplemented in addition to phosphorus with a mineral stock solution $(+150 \mu \mathrm{l}$ of IMR mineral stock solution). Cell concentration was monitored at intervals of several days. Nutrient content reduction was measured after the strains appeared to reach stationary phase.

\section{Results}

\subsection{Microalgae strain isolation and characterisation}

Overall, 34 strains were isolated and successfully brought into culture. Some cultures, although monoalgal, could be observed to undergo morphological changes or be prone to microbial contamination after a certain time. These cultures were not used further. Also, fibrous and pico plankton microalgae were difficult to evaluate for growth and were excluded. 25 strains were evaluated in the tolerance tests.

\subsection{Phylogenetic analyses}

Figure 1 displays a phylogenetic tree compiled from the sequences of isolated strains and typical representatives of the major microalgal taxonomic groups. The highest numbers of strains isolated were from the phyla Chlorophytes (16) and Bacillariophyta (7). Two strains of Cryptophyta and only one representative from the Euglenophyta, Rhodophyta and Prasinophyta were successfully brought into culture.

While strains from taxa Euglenophyta, Rhodophyta, Cryptophyta and Bacillariophyta formed clearly distinguished clades (bootstrap values $\sim 0.9$ ), the Chlorophyta was not clearly separated from representatives of phylum Prasinophyta.

\subsection{Tolerance studies}

\subsubsection{Stress response to different conductivity levels}

Most freshwater species showed growth at the higher conductivity tested. Some freshwater species did not grow at either lower or higher conductivity (i.e. 
OT12aTL, SW15aRL) and some cultures were highly prone to both bacterial and fungal contamination in the test media (i.e. SW05aTL, DI08aTL), especially the strains originally isolated from the landfill leachate.

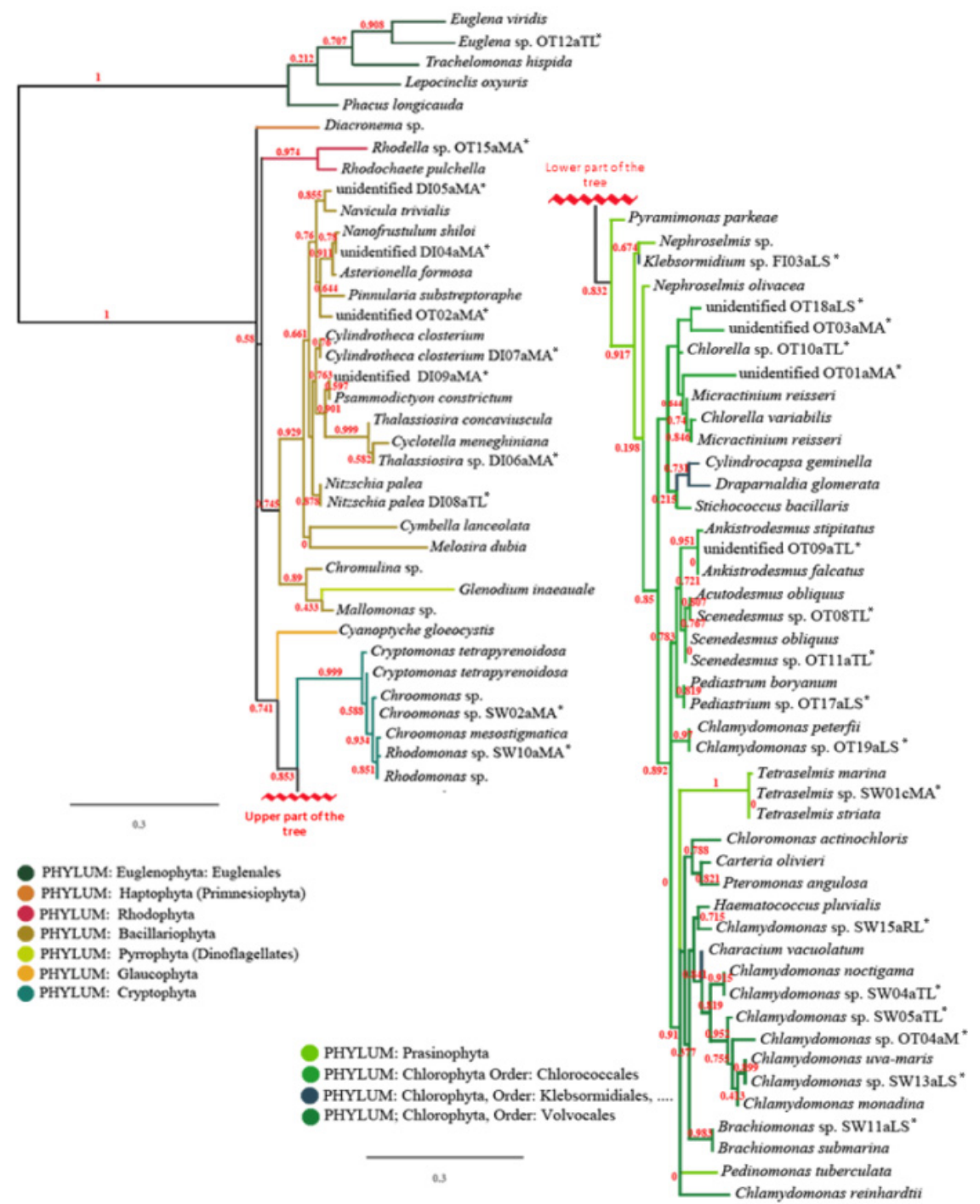

Figure 1: Unrooted phylogenetic tree produced from sequences obtained from isolated strains $(*)$ and sequences obtained from NCBI GeneBank Numbers at nodes represent bootstrap values.

Only one of all the marine cultures tested (OT14aMA) was able to tolerate the change of medium conductivity across the whole range and had comparable growth at all three tested conductivities (Figure 2). 
Two other cultures, OT03aMA and OT04aMA, showed survival at both lower tested conductivities. Strain SW07aMA appeared to be a brackish species as its growth at middle range conductivity exceeded that observed at the highest conductivity. This strain was however not able to adjust to the lowest conductivity medium.

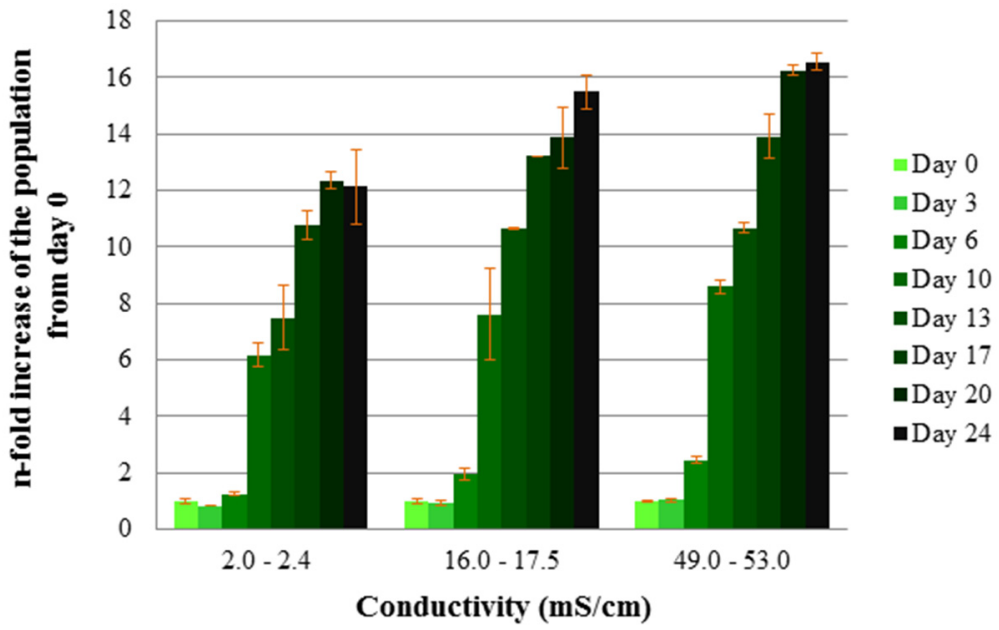

Figure 2: Tolerance of marine microalgae strain OT14aMA to media of different conductivities. OT14aMA was the only marine strain that was not affected in a major way by change of media conductivity without acclimatisation.

The overview of the adaptability of strains to different conductivities of media is displayed in Figure 3.

\subsubsection{Stress response to different leachate substrates}

The screening of microalgae strains in landfill leachate stress tests yielded 16 strains able to survive and/or grow. These were mainly freshwater species. Most of the marine species did not grow in any diluted leachate. Even those able to adapt to lower osmotic pressure (as seen from conductivity stress experiments) showed only moderate growth. The marine species that showed some growth were Tetraselmis sp. SW01cMA, that was able to grow at 25\% dilution (with sea water) of permeate and raw leachate, and the unidentified chlorophyte strain OT03aMA that also showed some growth in treated leachate. Strain OT14aMA was able to tolerate change of conductivity across the whole range and was originally tested during the leachate tolerance experiments using leachate diluted with low salinity dilution water. However, the strain did not appear to be able to adapt to a combination of leachate and change of conductivity within the time period tested. The test was repeated with leachate diluted with seawater and the strain was then able to grow.

Some strains, isolated mostly from landfill leachate, showed promising tolerance to different leachates and dilutions (e.g. SW05aTL, Figure 4). The 
results for the tolerance test were compiled and a table summarising species most likely to suit landfill leachate treatment are listed in Table 1.

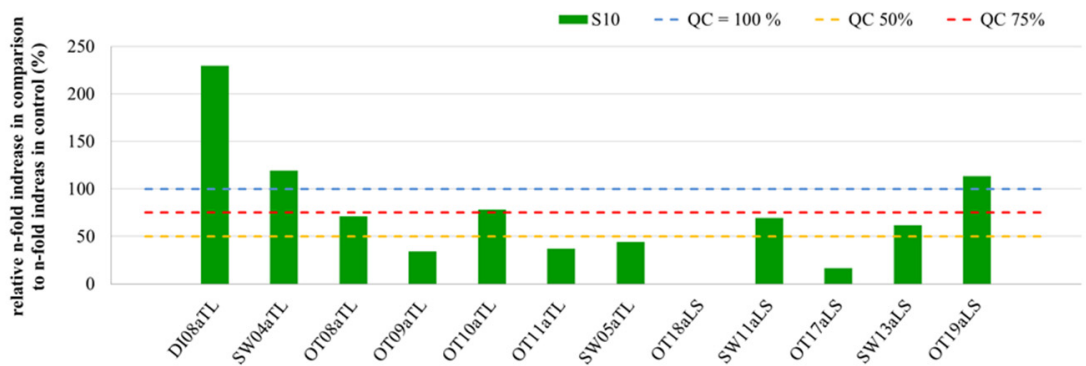

(a)

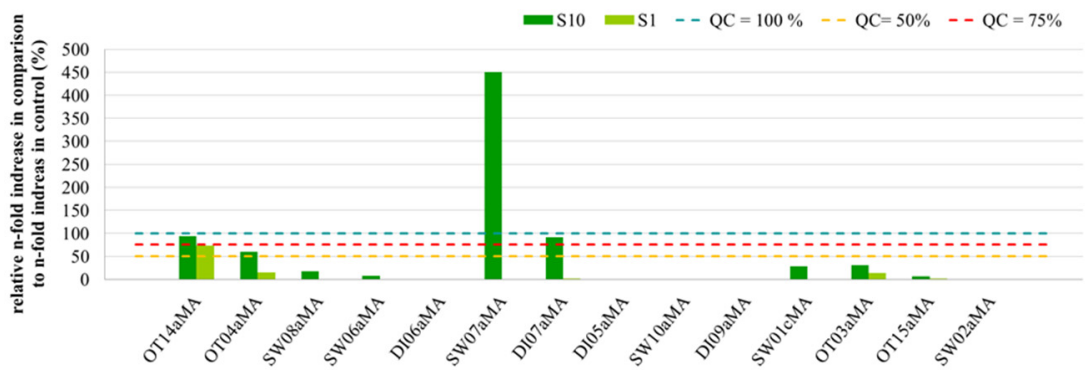

(b)

Figure 3: Tolerance of (a) freshwater and (b) marine microalgae to media with lower and higher conductivity (salt strength).
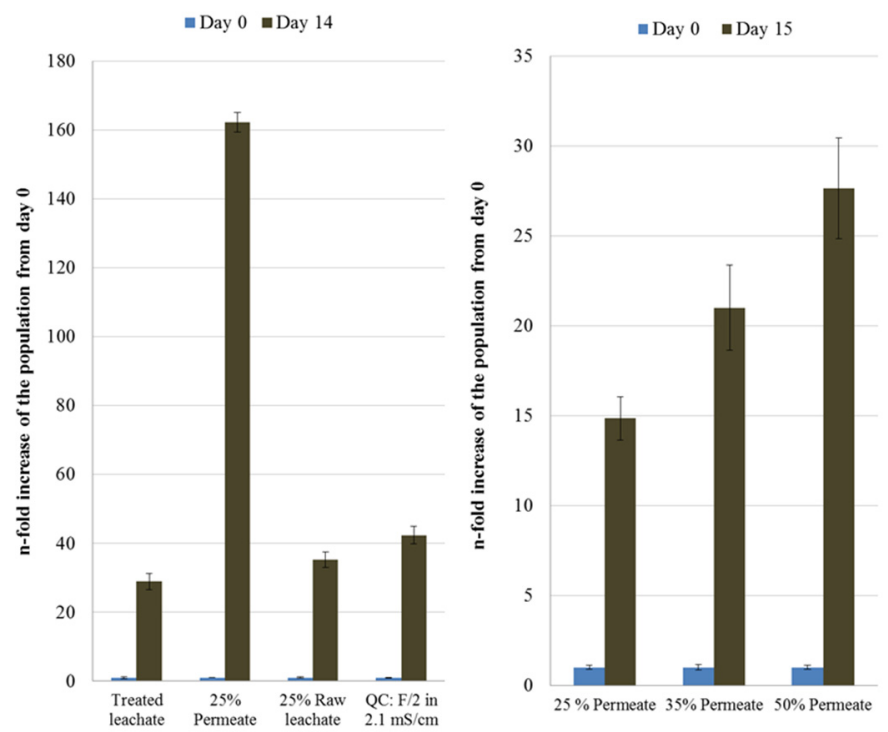

Figure 4: Leachate tolerance experiment results for strain SW05aTL. 


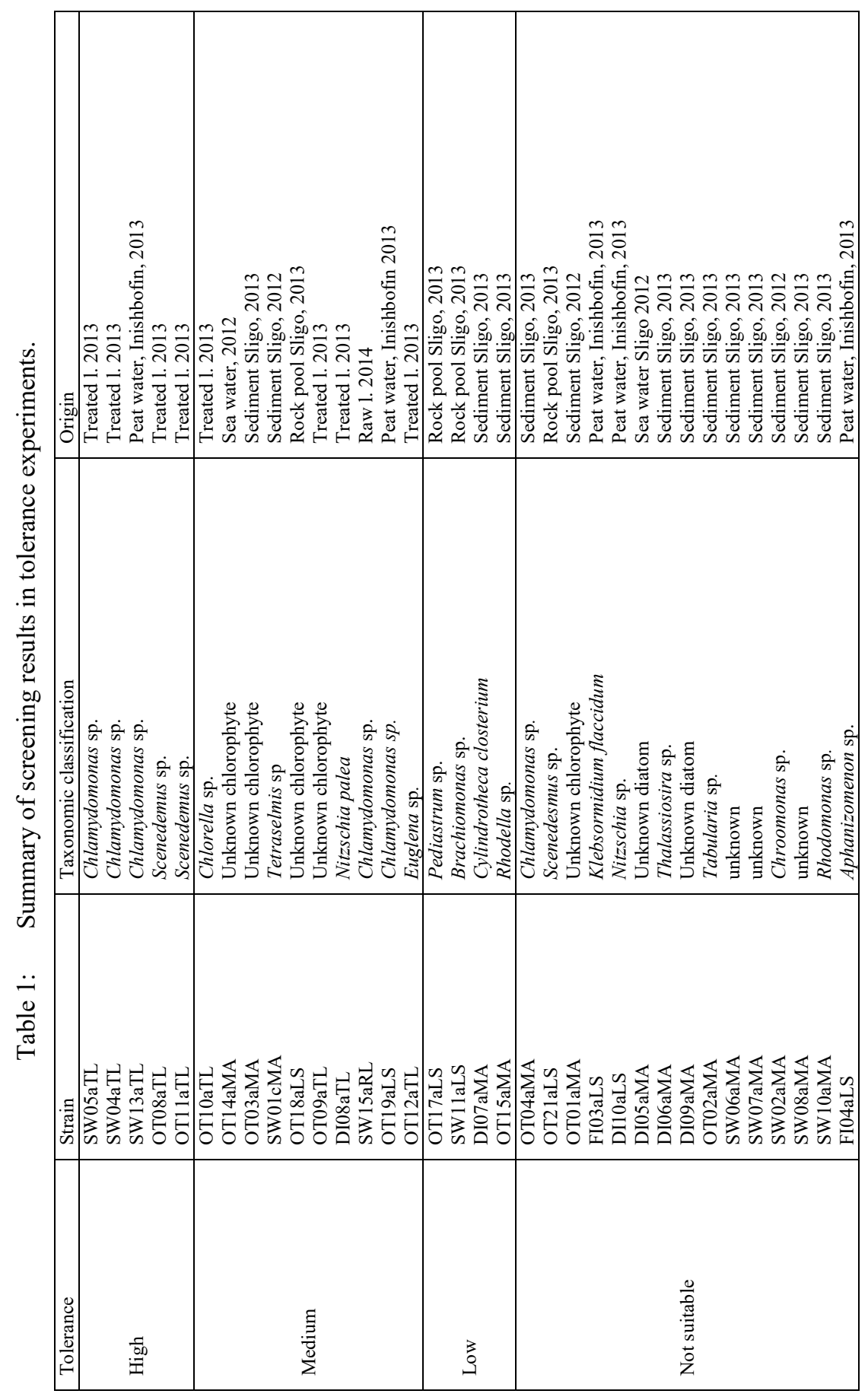




\subsection{Preliminary nutrient depletion experiment}

From the growth curves in Figure 5 it can be seen that the flasks supplemented with phosphorus both showed increased growth and achieved higher cell densities. In the flasks with no addition of phosphorus the growth stopped after approximately day 36. Nutrient depletion also confirmed the phosphorus limitation as there was clearly higher removal of nitrogen in phosphorus supplemented flasks (Table 2).

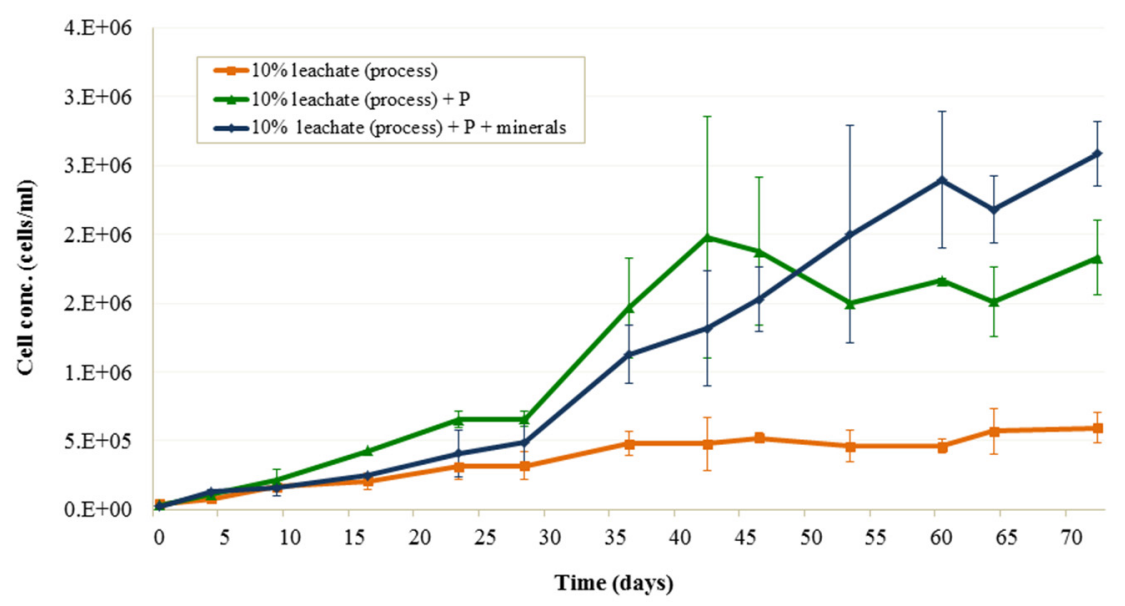

Figure 5: Growth curves of strain SW13aLS in 10\% permeate with and without nutrient supplementation.

Table 2: $\quad$ Change of nutrient concentration due to growth of Chlamydomonas sp. in $10 \%$ permeate with and without nutrient supplementation. Results on day 60 are averages of duplicates.

\begin{tabular}{|c|c|c|c|c|c|c|c|c|c|}
\hline & \multicolumn{3}{|c|}{$10 \%$ permeate } & \multicolumn{3}{|c|}{$\begin{array}{l}10 \% \text { permeate } \\
\left(+\mathrm{PO}_{4}^{3-}-\mathrm{P}\right)\end{array}$} & \multicolumn{3}{|c|}{$\begin{array}{c}10 \% \text { permeate } \\
\left.\left(+\mathrm{PO}_{4}^{3-}-\mathrm{P}\right) \text { and } \mathrm{min}\right)\end{array}$} \\
\hline & Day 0 & & Day 60 & Day 0 & & Day 60 & Day 0 & & Day 60 \\
\hline & $\begin{array}{l}\text { Conc. } \\
(\mathrm{mg} / \mathrm{l})\end{array}$ & $\begin{array}{l}\text { Conc. } \\
(\mathrm{mg} / \mathrm{l})\end{array}$ & $\begin{array}{c}\text { Reduction } \\
(\%)\end{array}$ & $\begin{array}{l}\text { Conc. } \\
(\mathrm{mg} / \mathrm{l})\end{array}$ & $\begin{array}{l}\text { Conc. } \\
(\mathrm{mg} / \mathrm{l})\end{array}$ & $\begin{array}{c}\text { Reduction } \\
(\%)\end{array}$ & $\begin{array}{l}\text { Conc. } \\
(\mathrm{mg} / \mathrm{l})\end{array}$ & $\begin{array}{l}\text { Conc. } \\
(\mathrm{mg} / \mathrm{l})\end{array}$ & Reduction \\
\hline $\mathrm{PO}_{4}^{3-}-\mathrm{P}$ & 1 & $<0.02$ & 98 & 41 & 5 & 88 & 41 & 32 & 22 \\
\hline TON & 95 & 87 & 8 & 95 & 44 & 54 & 95 & 61 & 36 \\
\hline $\mathrm{NH}_{4}^{+}-\mathrm{N}$ & 23 & 4.1 & 82 & 23 & 1.5 & 93 & 23 & *ND & 100 \\
\hline
\end{tabular}

*ND - not detected.

\section{Discussion}

\subsection{Screening procedure by tolerance studies}

Strains from various environments were included due to their potential to tolerate various substances or conditions. Marine species were chosen to be considered 
due to their resistance to high concentrations of dissolved salts. Also, a number of freshwater sites were included. For example, bog water (high content of humic substances) was considered due to potentially lesser light demand of the species present in this environment (as leachate can also be very dark). The species from landfill leachate were assumed to be adapted to the high ammonia-nitrogen and other substances present in landfill leachate.

The growth results from leachate/ammonia and conductivity tolerance experiments are indicatory. The effects of various ions concentrations are complex as they mutually influence cell growth through inhibition as well as microalgal nutrient requirements preference. The overall objective was to isolate a small number of microalgal strains best suited to these various conditions. The important factor evaluated was survival but also the ability to grow under new conditions, which was evaluated based on the number of divisions and biovolume increase.

As microalgae strain isolation started concurently with the selection of a wastewater type that could be used in this project, the inital medium used in this project was $\mathrm{f} / 2$ medium, which is commercially available in concentrated form. A wide range of cultures had been isolated from various environments: marine, brackish/coastal, peat water and eventually from a landfill leachate sample itself by the time a landfill leachate became available.

The initial screening highlighted that the species from the environment of the landfill tended to perform better in leachate stress studies and not so well in the conductivity tolerance experiments carried out with $\mathrm{f} / 2$ medium, in which their growth was relatively poor. In addition, the cultures originating from the landfill sample proved challenging to maintain within the laboratory as the $f / 2$ medium did not appear suitable. It seemed however satisfactory for coastal species, even for the strains isolated from rock pools with low conductivity water. Similar to previous studies where the chlorophytes dominate wastewater treatment application, in this study they were the most adaptable for growth in polluted waters as well [3-7].

\subsection{Importance of selecting a suitable growth medium}

Comparison of the average yearly composition of landfill leachate with some commonly used media for microalgal culturing could prove helpful in selecting more suitable media than the initially selected $f / 2$. None completely reflects the leachate profile. However, it can be reasonably assumed that the growth medium into which the microalgae strains are initially isolated provides an early bias in relation to their subsequent selection as it is more likely to promote growth of strains that are suited to that particular composition. Landfill leachate does have a relatively high conductivity caused by high concentrations of various salts, as reflected by high levels of chloride, high concentrations of sodium, calcium and magnesium in comparison with commercially available media (i.e. f/2, BG-11, BBM, TAP, HSM). This could be modulated either by addition of salts or by dillution of landfill leachate.

Nitrogen is present in raw, processed and treated leachate in high concentration. It is present in the form of ammonia rather than nitrate in raw leachate although some nitrate may be present. Processed leachate, which is partially treated 
leachate, contains both ammoniacal and oxidised nitrogen, while their total cumulative concentration is similar to that of raw leachate. Treated leachate on the other hand contains mostly nitrate at lower concentration and residual ammonia.

In this study, the screening process focused on the three different landfill leachates samples because both raw leachate treatment and treated leachate clarification were considered. Thus far, most raw landfill leachate phycoremediation attempts have required it to be diluted to make any microalgae growth possible $[3,4,19-21]$. It was suggested that this is mainly due to the toxic effect of ammonia. Thus relating this to the composition of standard media composition, a $10 \%$ dilution of average yearly raw leachate composition from the site used in 2013 in this study would have a similar ammonia content ( $\sim 90 \mathrm{mg} / 1$ $\mathrm{NH}_{4}^{+}-\mathrm{N}$ to $\mathrm{HSM}\left(\sim 131 \mathrm{mg} / \mathrm{l} \mathrm{NH}_{4}^{+}-\mathrm{N}\right)$, TAP $\left(\sim 98 \mathrm{mg} / \mathrm{l} \mathrm{NH}_{4}^{+}-\mathrm{N}\right)$ or SagerGranick $\left(\sim 79 \mathrm{mg} / 1 \mathrm{NH}_{4}^{+}-\mathrm{N}\right)$ media. High $\mathrm{N}: \mathrm{P}$ molecular ratio in leachate in comparison to the Redfield ratio is often viewed as an indication of nutrient requirements for algal growth and points to indicate possible phosphorus limitation. Also, if leachate is diluted, possibly some nutrients that were originally present at comparable concentrations to standard media will become reduced (e.g. iron, zinc or magnesium).

\subsection{Nutrient depletion}

The nutrient depletion experiment showed that reduction in pollutants is possible. This appeared to be phosphate limited as this nutrient is present at very low concentrations proportionaly to nitrogen. Also the timescale required for growth to take place was very long.

\subsection{Future work}

A number of microalgae strains selected via a screening process will be evaluated for their ability to reduce nutrients, ammonia-nitrogen, total oxidised nitrogen and phosphate. While autoclaved leachate samples were used in isolation of microalgae strains and initial screening, this process is thought to alter the physicochemical profile of leachate and this will be investigated further. This process is also not sustainable for practical remediation applications. Lastly, the landfill leachate physico-chemical profile indicated possible phosphate limitation for microalgae growth and thus should be investigated further.

\section{Conclusion}

The screening process yielded a number of promising strains for treatment of landfill leachate. These were primarily freshwater species and were mainly isolated from landfill leachate. While these strains performed well in screening tests, it proved difficult to maintain them within the laboratory and interestingly even standard media containing ammonia-nitrogen (TAP, HSM) did not seem to suit some strains. These started to undergo changes (i.e. formation of palmelloids in SW04aTL and SW05aTL). Thus, while certain strains showed major growth in a particular leachate they also seemed more sensitive to composition variations, 
possibly at a micronutrient level. On the other hand, the species growing across a wider range of substrates showed more moderate growth.

\section{Acknowledgements}

This work has been supported by Institute of Technology Sligo Presidents Bursary Scheme. We also wish to thank employees of the landfill site for their assistance in providing landfill leachate which is greatly appreciated.

\section{References}

[1] Olguín, E.J., Phycoremediation: key issues for cost-effective nutrient removal processes, Biotechnology Advances, 22, pp. 81-91, 2003.

[2] Johannessen, L. M., Guidance Note on Leachate Management for Municipal Solid Waste Landfills, The International Bank for Reconstruction and Development/The World Bank, USA, 1999.

[3] Cheng, H.-X., Tian, G.-M., Preliminary Evaluation of a Newly Isolated Microalga Scenedesmus sp. CHX1 for Treating Landfill Leachate, 2013 Third Int. Conf. Intell. Syst. Des. Eng. Appl., pp. 1057-1060, 2013.

[4] Lin, L., Chan, G.Y.S., Jiang, B.L., Lan, C.Y., Use of ammoniacal nitrogen tolerant microalgae in landfill leachate treatment, Waste Management, 27, pp. 1376-1382, 2007.

[5] Mustafa, E.M., Phang, S.M., Chu, W.L., Use of an algal consortium of five algae in the treatment of landfill leachate using the high-rate algal pond system, Journal of Applied Phycology, 24(4), pp. 953-963, 2012.

[6] Abou-Shanab, R.A.I., Ji, M.K., Kim, H.C., Paeng, K.J., Jeon, B.H., Microalgal species growing on piggery wastewater as a valuable candidate for nutrient removal and biodiesel production, Journal of Environmental Management, 115, pp. 257-264, 2013.

[7] Zhou, W., Li, Y., Min, M., Hu, B., Chen, P., Ruan, R., Local bioprospecting for high-lipid producing microalgal strains to be grown on concentrated municipal wastewater for biofuel production, Bioresource Technology, 102(13), pp. 6909-6919, 2011.

[8] Craggs, R.J., Mcauley, P.J., Smith, V.J., Wastewater Nutrient Removal by Marine Microalgae Grown on a Corrugated Raceway, Water Research, 31, pp. 1701-1707, 1997.

[9] Jiang, L., Luo, S., Fan, X., Yang, Z., Guo, R., Biomass and lipid production of marine microalgae using municipal wastewater and high concentration of CO2, Applied Energy, 88, pp. 3336-3341, 2011.

[10] Aravantinou, A.F., Theodorakopoulos, M., Manariotis, I.D., Selection of microalgae for wastewater treatment and potential lipids production, Bioresource Technology, 147, pp. 130-134, 2013.

[11] Tomas, C. R., Identifying Marine Phytoplankton, Academic Press, UK, ISBN-13: 978-0-12-693018-4, 1997.

[12] John, D. M., Whitton, B. A., Brook, A. J., The Freshwater Algal Flora of the British Isles: An Identification Guide to Freshwater and Terrestrial Algae, 
The Natural History Museum and the British Phycological Society, UK, ISBN 052177051 3, 2002.

[13] Touzet, N., Franco, J.M., Raine, R., Characterization of nontoxic and toxinproducing strains of Alexandrium minutum (Dinophyceae) in Irish coastal waters, Applied Environmental Microbiology, 73, pp. 3333-3342, 2007.

[14] Castresana J., Selection of conserved blocks from multiple alignments for their use in phylogenetic analysis, Molecular Biology and Evolution, 17(4), pp. 540-552, 2000.

[15] Dereeper, A., Guignon, V., Blanc, G., Audic, S., Buffet, S., Chevenet, F., Dufayard, J.F., Guindon, S., Lefort, V., Lescot, M., Claverie, J.M., Gascuel, O., Phylogeny.fr: robust phylogenetic analysis for the non-specialist, Nucleic Acids Research, 36(Web Server issue):W465-9. doi: 10.1093/nar/gkn180. Epub 2008 Apr 19, 2008.

[16] Edgar R.C., MUSCLE: multiple sequence alignment with high accuracy and high throughput, Nucleic Acids Research, 32(5), pp. 1792-1797, 2004.

[17] Guindon, S., Dufayard, J.F., Lefort, V., Anisimova, M., Hordijk, W., Gascuel, O., New Algorithms and Methods to Estimate MaximumLikelihood Phylogenies: Assessing the Performance of PhyML 3.0., Systematic Biology, 59(3), pp. 307-321, 2010.

[18] Anisimova M., Gascuel O., Approximate likelihood ratio test for branchs: A fast, accurate and powerful alternative, Systematic Biology, 55(4), pp. 539$552,2006$.

[19] Sforza, E., Al, M.K., Sharif, A., Exploitation of Urban Landfill Leachate as Nutrient Source for Microalgal Biomass Production, Chemical Engineering Transactions, 43, 2015.

[20] Thongpinyochai, S., Ritchie, R.J., Using Chlorella vulgaris to Decrease the Environmental Effect of Garbage Dump Leachates, Journal of Bioremediation \& Biodegradation, 5(5)., pp. 1-12, 2014.

[21] Zhao, X., Zhou, Y., Huang, S., Qiu, D., Schideman, L., Chai, X., Zhao, Y., Characterization of microalgae-bacteria consortium cultured in landfill leachate for carbon fixation and lipid production, Bioresource Technology, 156, pp. 322-328, 2014. 